\title{
Organolead(IV) triacetates in organic synthesis
}

\author{
John T. Pinhey \\ School of Chemistry, University of Sydney, Sydney 2006, Australia
}

\begin{abstract}
Organolead triacetates have been developed as relatively cheap and versatile reagents for the electrophilic arylation, vinylation and alkynylation of soft carbon nucleophiles. Their reactions with phenols and $\beta$-dicarbonyls, in particular, illustrate their unique regioselectivity in which they display a marked preference for the generation of quaternary cabon centres. This aspect of their reactivity has been put to use in a number of natural product syntheses and can result in the formation of highly hindered structures. The main features of these reactions and their mechanisms, which are shown to involve ligand coupling, are discussed.
\end{abstract}

\section{INTRODUCTION}

Aryllead triacetates have been known for about 40 years (1), but only during the last 15 years has their potential as electrophilic arylating agents been recognised (2-4). Following the discovery of this reactivity a search for better methods of synthesis resulted in the introduction of two very general procedures; these involve Sn-Pb exchange (5) and $\mathrm{B}-\mathrm{Pb}$ exchange (6), methods which can also be applied to the generation of vinyllead triacetates (7) and alk-1ynyllead triacetates (8) as illustrated in the following examples. Unlike the aryllead triacetates the vinylic and acetylenic compounds are relatively unstable; with half lives of a few minutes at room temperature they must be generated just prior to their use.<smiles>COc1cc(O)cc(Br)c1</smiles>

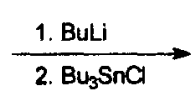<smiles>CCCCCCCCCCCCCCC</smiles><smiles>COc1ccc([P+]([O-])O[Na])cc1OC</smiles><smiles>Fc1ccccc1</smiles>

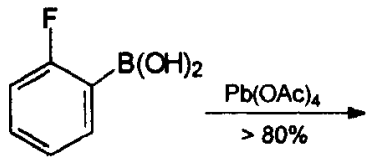<smiles>O=C(O)Oc1ccccc1F</smiles><smiles>CSC1=CCCCC1</smiles><smiles>CCC(C)C(C)(C)OC(C)(C)C</smiles><smiles>CC(C)(C)OOC(=O)C1=CCCCC1</smiles>

$\mathrm{Me}_{3} \mathrm{SiC} \equiv \mathrm{CSnMe}_{3}$

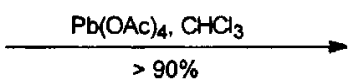

$\mathrm{Me}_{3} \mathrm{SiC} \equiv \mathrm{CPb}(\mathrm{OAC})_{3}$

Plumbation of aromatics with $\mathrm{Pb}(\mathrm{OAc})_{4}$ is the most direct route to the aryllead compounds $(4,9)$; however, unlike the related mercuration and thallation reactions, it is limited in scope to aromatics more reactive than fluorobenzene. 
Our study of the chemistry of aryl-, vinyl- and alk-1-ynyl- lead triacetates has shown that they undergo four main types of reactions. These are (a) metal-metal exchange, such as that with boronic acids which provides a very useful route to diorganolead diacetates (10), (b) acid catalysed heterolytic cleavage of the $\mathrm{C}-\mathrm{Pb}$ bond, from

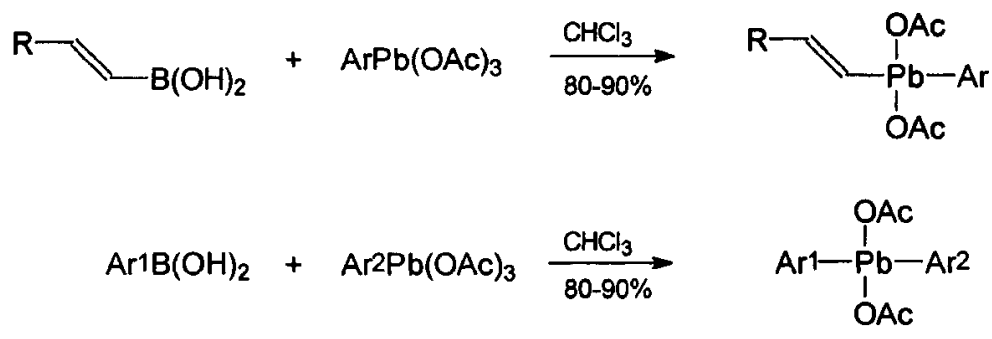

which potentially useful phenol (4) and aryl fluoride (11) syntheses have been developed, (c) the copper catalysed

$$
\mathrm{ArPb}(\mathrm{OAC})_{3} \stackrel{\mathrm{H}^{+}}{\longrightarrow} \mathrm{Ar}^{+}+\mathrm{Pb}(\mathrm{OAC}) 2+\mathrm{HOAC}, \stackrel{\mathrm{Ar}^{+}}{\mathrm{N}^{-}} \longrightarrow \mathrm{ArN}
$$

arylation of amines, which was introduced by Sir Derek Barton (12), and (d) the displacement of $\mathrm{Pb}(\mathrm{OAc})_{3}$ by soft nucleophiles, especially carbon nucleophiles, a reaction believed to involve ligand exchange followed by ligand coupling (13), and which is the subject of this report.

\section{ortho-SUBSTITUTION OF PHENOLS BY LIGAND COUPLING}

The reaction of phenols with organolead triacetates was originally thought to be restricted to phenols substituted in at least one of the ortho positions by an alkyl or methoxy group (2) as shown for mesitol. Analogous reactions occur with vinyllead and alk-1-ynyllead triacetates to yield products with considerable synthetic potential (14); however, since this paper is devoted to the mechanistic aspects of the reaction, vinylation and alkynylation will not be discussed here since the instability of the lead compounds precluded their use in such a study.

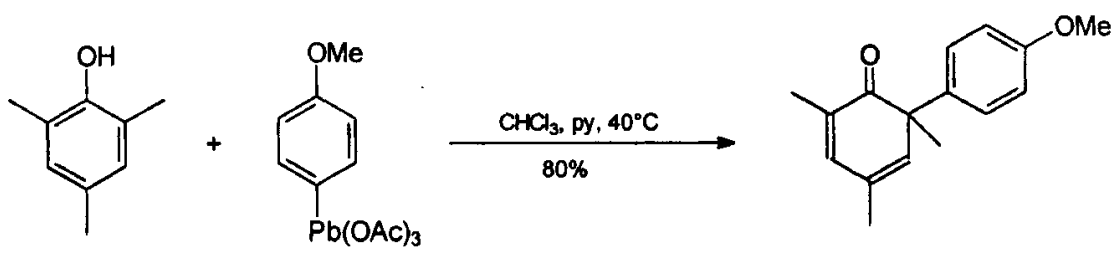

A significant feature of reactions of aryllead triacetates with phenols and many other carbon nucleophiles is the need to include 2-3 mol. equivalents of a base capable of coordinating with $\mathrm{Pb}$. When excluded, the yield of arylated product is reduced and a considerable amount of the corresponding o-acetoxy product is formed. An investigation of the effect of other bases showed that the rates of reactions and yields were related to their ability to coordinate with $\mathrm{Pb} ; 1,10$-phenanthroline was more effective than 2,2'-bipyridyl which resulted in faster reactions than pyridine. Therefore, it appears that an intermediate in which $\mathrm{Pb}$ is coordinated to at least 2 nitrogens is involved in arylation. There is supporting evidence for this coordination from an NMR spectroscopic examination of the effect of the addition of pyridine on the chemical shift of the ortho hydrogens of $p$-anisyllead triacetate; there is a large downfield shift relative to the signal for those meta to $\mathrm{Pb}$ which reaches a maximum on addition of 2-3 mol. equivalents.

For methyl subtituted phenols the reaction rate and yield of 6-arylated-2,4-cyclohexadienone is dependent on the number of methyl substituents. The order of reactivity has been shown to be 2,4,6-trimethylphenol (mesitol) $>2,6$ dimethylphenol $>2,4$-dimethylphenol $>o$-cresol; $p$-cresol and phenol fail to react. Therefore, it appeared from the earlier work that one ortho methyl was required for the reaction. However, recently it has been found that arylation proceeds with phenols substituted by 2 or more methyl groups but not necessarily occupying either of the ortho positions. As indicated below, both 3,4,5-trimethylphenol and 3,5-dimethylphenol undergo relatively rapid 
diarylation. to yield terphenyls, while Barton had shown earlier that 3,5-di-t-butylphenol underwent the same reaction (15). In that work it was found that 2,4,6-trimethoxyphenyllead triacetate reacted readily with this phenol to give an extremely hindered terphenyl. Here again it was shown that the rate of arylation was faster for the more methylated phenol, and, surprisingly, arylations with 2,4,6-trimethoxyphenyllead triacetate- were faster than with $p$ anisyllead triacetate even with phenol 3.

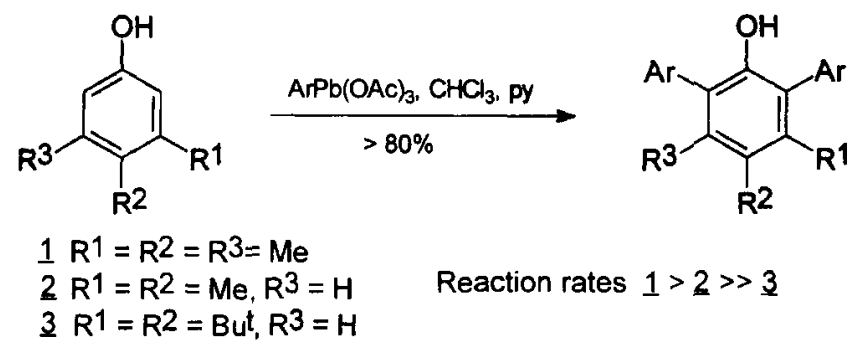

The work with alkylated phenols has shown that (a) reactivity of phenols to arylation increases with their $\pi$-donor properties, (b) there is a strong preference for reaction at a substituted ortho position rather than an unsubstituted one, even though there is a loss of aromaticity, (c) arylation leading to highly hindered structures occurs readily at room temperature, and (d) aryl radicals are not involved in the reaction.

The exclusion of mechanisms involving aryl radicals was firmly established by the reaction shown below between mesitol and $\alpha$-allyloxyphenyllead triacetate in which the aryl group contained an internal trap; no dihydrobenzofurans were produced (16). The potential free radical exo-trig cyclisation of the $o$-allyloxy group is very fast, and this probe has been used successfully to establish the intermediacy of aryl radicals in the reaction of diazonium salts with iodide (17) and in a number of $S_{\mathrm{RN}} 1$ processes (18).<smiles>C=CCOc1ccccc1C1(C)C=C(C)C=C(C)C1=O</smiles>

The elimination of free radical mechanisms for the arylation led to the conclusion that ligand coupling was occurring. There appeared to be two possibilities for the intermediate produced in the initial ligand exchange with mesitol, species 4 and 5. Since attempts to observe an intermediate by ${ }^{1} \mathrm{H}$ and ${ }^{207} \mathrm{~Pb}$ NMR spectroscopy failed, a synthetic approach was adopted. This had become possible with the recent finding of the high reactivity to arylation of 3,4,5-trimethylphenol. By use of our $\mathrm{B}-\mathrm{Pb}$ exchange (10) the diaryllead diacetate 6 was readily produced in high yield. This compound was quite stable in $\mathrm{CHCl}_{3} /$ pyridine at $60^{\circ} \mathrm{C}$, and failed to yield a biaryl even in refluxing DMSO.<smiles>CC(=O)O[Pb]([Te])(OC(C)=O)Oc1c(C)cc(C)cc1C</smiles>

4<smiles>CC(=O)O[Pb]([Te])(OC(C)=O)C1(C)C=C(C)C=C(C)C1=O</smiles>

5<smiles>COc1ccccc1P(=O)(OC(C)=O)c1c(OC)cc(C)c(C)c1C</smiles>

$\underline{6}$

Therefore, we believe that ligand coupling occurs in an intermediate such as 4, in which there is an overlap of the $\pi$ systems of the phenolate ligand and the Pb-bound aryl group as originally proposed by Barton (15). Such a mechanism is in keeping with the finding that the greater the $\pi$-donor capacity of the phenol the faster the reaction. A significant feature of the reaction, which distinguishes it from an electrocyclic reaction such as the Claisen rearrangement of allyl aryl ethers in which steric factors prevail, is the preference for arylation at a methyl substituted ortho position. This would indicate that the aryl group has electrophilic character, reacting at the more electron rich site. 


\section{$\alpha$-Substitution of $\beta$-Dicarbonyl Compounds by Ligand Coupling}

The reaction of $\beta$-dicarbonyl compounds with organolead triacetates occurs under similar conditions to those developed for phenols. As indicated, a coordinating base is again required for arylation,and their effectiveness was found to be the same as with phenol arylation, 1,10-phenanthroline $>2,2$ '-bipyridyl $>$ pyridine.

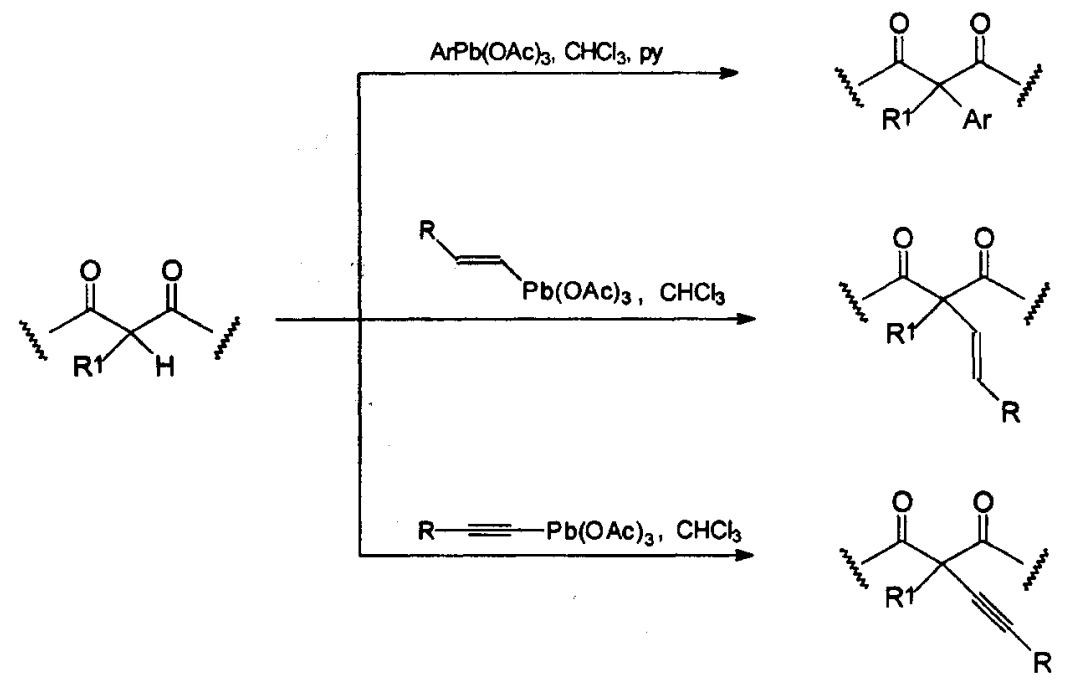

In general the reaction proceeds best and is more predictable in compounds containing only one $\alpha$-hydrogen (4). In compounds with $2 \alpha$-hydrogens diarylation often results, with the second reaction being faster than the initial arylation. However, in some cases, such as in 4-hydroxycoumarins, the reaction can be controlled to give high yields of 3-aryl-4-hydroxycoumarins, providing a convienent route to some naturally occurring isoflavanoids (19).

The regioselectivity mirrors that of phenol arylation; in a number of vinylogous $\beta$-dicarbonyls, arylation, vinylation and alkynylation reactions occur to generate quaternary carbon centres rather than tertiary (4). In both the examples below none of the product of attack alpha to the other carbonyl group was formed.

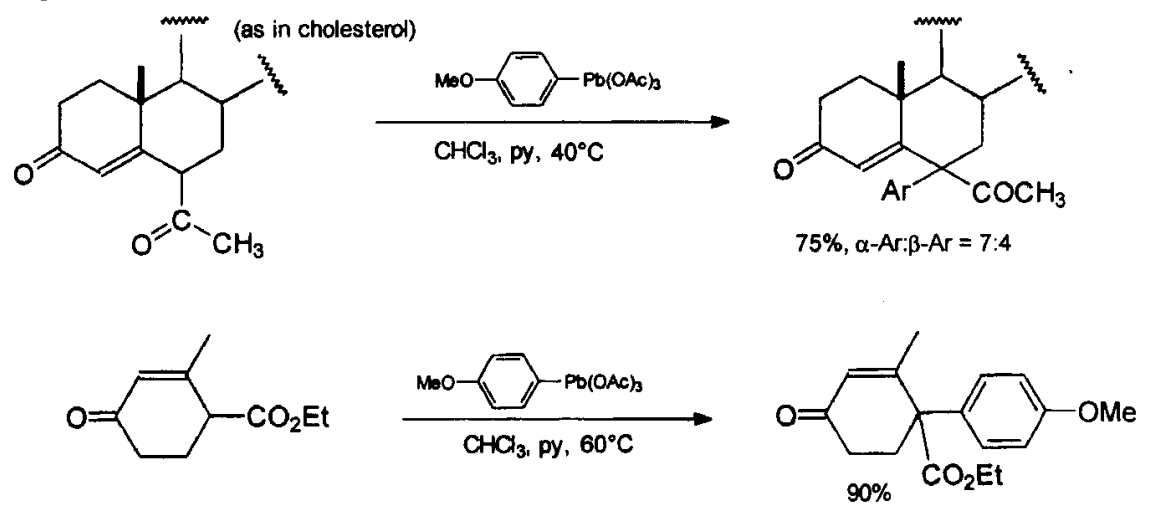

Analogous arylations of ethyl 4-oxocyclohex-2-enecarboxylate, have been employed in short high-yielding syntheses of the alkaloids ( \pm -mesembrine (20) and ( \pm )-lycoramine (21). As with phenols, electron density at the reaction site is important for successful reaction. This is well illustrated by the failure of the potassium enolate of cyclohexanone to undergo arylation with $p$-anisyllead triacetate, whereas the potassium enolate of 2,6dimethylcyclohexanone reacts readily wih the same lead compound to give a mixture of isomeric 2-aryl-2,6 dimethylcyclohexanones in $75 \%$ yield. Consistent with these results, only the more substituted enolate of $2-$ methylcyclohexanone reacts, to yield 2-(p-anisyl)-2-methylcyclohexanone.<smiles>[Z]C=C1CCCC1(CCC)c1ccccc1OCC=C</smiles>

As indicated above, our attention has turned to the mechanism of arylation of $\beta$ dicarbonyls. The exclusion of pathways involving aryl radicals was achieved in a similar way to that used with phenols; Barton found that the addition of 1,1-diphenylethylene had no effect on the phenylation of ethyl 2-oxocyclohexanecarboxylate (22), while we have shown that 2-allyloxyphenyllead triacetate reacted with ethyl 2-oxocyclopentanecarboxylate to give only the product of simple arylation 7 in $>90 \%$ yield (16). 
With a ligand coupling mechanism appearing to be the most likely candidate we attempted to observe the possible<smiles>[R]C(C)(C(C)(C)C(=O)O)[Pb]([R])(OC(C)=O)OC(C)=O</smiles>

8<smiles>[R]/C(CC)=C(/CC)OP(=O)([Te])O[Ge]</smiles>

9

intermediates 8 and 2 by ${ }^{1} \mathrm{H}$ and ${ }^{207} \mathrm{~Pb}$ NMR spectroscopy in a number of arylations without success. Despite this, there is now strong indirect support for a coupling pathway involving a carbon bound $\mathrm{Pb}(\mathrm{IV})$ intermediate of type 8 from the reaction of a group of silyl enol ethers (23). In this study a number of silyl enol ethers of alkyl phenyl ketones were reacted with $p$-anisyllead triacetate in the presence of a catalytic amount of $\mathrm{BF}_{3} \cdot \mathrm{Et}_{2} \mathrm{O}$ to give $p$-anisyl(phenacyl)lead diacetates 10 in high yield. All of these diorganolead diacetates (except where both $R^{1}$ and $\mathrm{R}^{2}=\mathrm{H}$ ) were thermally unstable at $60^{\circ} \mathrm{C}$, undergoing a ligand coupling to yield the substituted deoxybenzoin 11 and $\mathrm{Pb}(\mathrm{OAc})_{2}$. In some cases the $\alpha$-aryl ketone 11 was accompanied by the corresponding $\alpha$-acetoxy ketone, but no symmetrical products from intermolecular coupling were produced.<smiles>[R]C([R])=C(OC)c1ccccc1</smiles>

In addition, when the diorganolead compound 12 was heated at $60^{\circ} \mathrm{C}$ only the $\alpha$-aryl ketone 13 and $\alpha$-acetoxy ketone 14 were produced. The absence of products containing the dihydrobenzofuran structure excluded mechanisms involving radicals and pointed to a ligand coupling pathway to the products. Significantly the<smiles>C=CCOc1ccccc1C(C)C(=O)c1ccccc1C(=O)CCCCCCCC</smiles>

aryl(phenacyl)lead diacetates 10 showed the features expected for them if compounds of the same type were involved as intermediates in $\beta$-dicarbonyl arylation. For a particular aryllead triacetate the rate of formation of diorganolead compound 10 decreased in the series $R^{1}=R^{2}=H>R^{1}=H, R^{2}=M e>R^{1}=R^{2}=M e$; however, the stability of compound 10 decreased in the order $R^{1}=R^{2}=H>R^{1}=H, R^{2}=M e>R^{1}=R^{2}=$ Me. As would be expected $p$-anisyl( $\alpha, \alpha$-dimethylphenacyl)lead diacetate $\left(10, R^{1}=R^{2}=M e\right)$, which on ligand coupling produced a quaternary carbon centre, was the least stable compound of the series, being too unstable to permit full characterisation.

An attempt to produce lead compounds of type 10 by reaction of silyl enol ethers of $\beta$-dicarbonyl compounds with aryllead triacetates under similar conditions resulted only in the formation of the arylated $\beta$-dicarbonyl compound. No intermediates could be detected. This is, however, not surprising in view of the effect of $\alpha$-substitution on the stability of compounds of type 10 . Since an $X$-ray molecular structure of compound $\left(10, R^{1}=M e, R^{2}=H\right)$ showed<smiles>[Y]C(=O)C([R])([Y])[P+]([Al])(OC(C)=O)OC(C)=O</smiles> 
$\mathrm{Pb}$ to be heptacovalent with pentagonal bipyramidal geometry in which the carbon bound groups occupy roughly axial positions, we believe the coupling reaction of carbonyl compounds occurs as shown with the seventh coordination site omitted for clarity (Note a). The organolead triacetate undergoes an initial ligand exchange to produce a species in which the carbon bound ligands are in a trans configuration. A thermal pseudorotation of the phenacyl group then leads to a cis arrangement in which ligand coupling can occur, resulting in a thermodynamically favourable change in the oxidation state of lead from $\mathrm{Pb}(\mathrm{IV})$ to $\mathrm{Pb}(\mathrm{II})$.

\section{Acknowledgements}

Thanks are due to all my coworkers whose names are listed in the references below. A special thanks is due to Professor Sir Derek Barton whose interest and exchange of information during the course of this work were invaluable. Financial support from the Australian Research Council is gratefully acknowledged.

\section{References}

1. H. Shapiro and F.W. Frey, The Organic Compounds of Lead, Wiley, New York (1968).

2. H.C. Bell, J.T. Pinhey and S. Sternhell, Aust. J. Chem. 32, 1551 (1979).

3. J.T. Pinhey and B.A. Rowe, Aust. J. Chem. 32, 1561 (1979).

4. J.T. Pinhey, Aust. J. Chem. 44, 1353 (1991).

5. R.P. Kozyrod, J. Morgan and J.T. Pinhey, Aust. J. Chem. 38, 1147 (1985).

6. J. Morgan and J.T. Pinhey, J. Chem. Soc., Perkin Trans. 1, 715 (1990).

7. M.G. Moloney, J.T. Pinhey and M.J. Stoermer, J. Chem. Soc., Perkin Trans. 1, 2645 (1990).

8. M.G. Moloney, J.T. Pinhey and E.G. Roche, J. Chem. Soc., Perkin Trans. 1, 333 (1989).

9. L.C. Willemsens, D. de Vos, J. Spierenburg and J Wolters, J. Organomet. Chem. 39, C61 (1972).

10. J. Morgan, C.J. Parkinson and J.T. Pinhey, J. Chem. Soc., Perkin Trans. 1, 3361 (1994).

11. G.V. De Meio, J. Morgan and J.T. Pinhey, Tetrahedron, 49, 8129 (1993).

12. D.H.R. Barton, D.M.X. Donnelly, J.P. Finet and P.J. Guiry, J. Chem. Soc., Perkin Trans. 1, 2095 (1991).

13. S. Oae and Y. Uchida, Acc. Chem. Res. 24, 202 (1991).

14. T.W. Hambley, R.J. Holmes, C.J. Parkinson and J.T. Pinhey, J. Chem. Soc., Perkin Trans. 1, 1917 (1992).

15. D.H.R. Barton, D.M.X. Donnelly, P.J. Guiry and J.P. Finet, J. Chem. Soc., Perkin Trans. 1, 2921 (1994).

16. J. Morgan and J.T. Pinhey, J. Chem.Soc., Perkin Trans. 1, 1673 (1993).

17. A.L.J. Beckwith and G.F. Meijs, J. Org. Chem. 52, 1922 (1987).

18. A.L.J. Beckwith and S.M. Palacios, J. Phys. Org. Chem. 4, 404 (1991).

19. D.H.R. Barton, D.M.X. Donnelly, J.P. Finet and P.J. Guiry, J. Chem. Soc., Perkin Trans. 1, 1365 (1992).

20. C.J. Parkinson and J.T. Pinhey, J. Chem. Soc., Perkin Trans. 1, 1053 (1991).

21. D.J. Ackland and J.T. Pinhey, J. Chem. Soc., Perkin Trans. 1, 2695 (1987).

22. D.H.R. Barton, J.P. Finet, C. Giannotti and F. Halley, J. Chem. Soc., Perkin Trans. 1, 241 (1987).

23. J. Morgan, I Buys, T.W. Hambley and J.T. Pinhey, J. Chem. Soc., Perkin Trans. 1, 1677 (1993).

Note a: The molecule in fact forms a dimer in which one oxygen of each half of the dimer is shared between the two $\mathrm{Pb}$ atoms. 